FIX, Mariana. 2001. Parceiros da exclusão — duas histórias da construção de uma "nova cidade" em São Paulo : Faria Lima e Água Espraiada. São Paulo : Boitempo.

\title{
O ESTADO, O CAPITAL E A "NOVA CIDADE” DE SÃO PAULO
}

\author{
Wagner T. Iglecias \\ Universidade de São Paulo
}

\begin{abstract}
Parceiros da exclusão trata do maior processo de renovação urbana ocorrido na cidade de São Paulo nas últimas décadas. Relata, por meio da incursão etnográfica da autora no teatro de operações no qual se construiu, em meados dos anos noventa, a mais recente centralidade paulistana: a tentativa de resistência de dois grupos distintos de moradores da capital paulista diante da marcha avassaladora do capital imobiliário, convenientemente sustentada pelo poder público, sobre a porção sudoeste do município. É nessa região da cidade que se tem formado o maior distrito de negócios da América Latina, concentrando as filiais brasileiras de corporações transnacionais do setor terciário avançado. Mariana parte de uma hipótese largamente utilizada por diversos autores, como Heitor Frúgoli e Raquel Rolnik, de que São Paulo, durante o século passado, experimentou não apenas um crescimento desmesurado em direção à periferia, mas também um processo contínuo de criação e abandono de centralidades, a partir da função desempenhada pela metrópole, ao longo das décadas, na economia brasileira e nas conexões desta com o mundo (ROLNIK, 1988; FRÚGOLI, 2000). Voltada para a porção sudoeste da cidade, essa sucessão de centralidades tem como ponto de chegada a região retratada por Parceiros da exclusão. Trata-se de uma espécie de novo centro, denominado pela autora de "nova cidade", para onde convergiram, durante os anos noventa, vultosos volumes de recursos públicos e privados.
\end{abstract}

O enredo da construção dessa "nova cidade" é relativamente simples e já bastante conhecido. Partindo da premissa de que a terra é antes valor de troca que valor de uso, o capital imobiliário necessita, para produzir e multiplicar seus lucros, da constante abertura de novas fronteiras no espaço urbano (MARICATO, 1996; ROLNIK, 1997). O Estado, quando colocado a serviço dessa lógica, participa por meio da criação de infraestrutura (avenidas, meios de transporte etc.) voltada a viabilizar a valorização das terras. Muitas vezes, como no caso das histórias retratadas por Mariana, cabe ainda ao poder público realizar o serviço sujo de expulsão das populações de baixa renda situadas em terrenos cobiçados pelo capital imobiliário. Em Parceiros da exclusão fazem parte desse enredo novos atores como o capital financeiro - representado pelos fundos de pensão e que têm investido na construção dos grandes e modernos edifícios na região sudoeste da capital paulista e as corporações transnacionais - que chegaram ao Brasil nos anos noventa e passaram a ocupar os imóveis na condição de locatárias. Some-se à trama os moradores de classe média de bairros como Pinheiros, Itaim e Vila Olímpia, por onde foi rasgada a extensão da Avenida Brigadeiro Faria Lima (Nova Faria Lima), e os moradores das favelas do Jardim Edith, no Brooklin, por onde se construiu a Avenida Água Espraiada. Acrescente-se ainda a mídia e os especialistas em questões urbanas, que desempenharam papel controverso no processo, e tem-se o elenco daquilo que foi a criação da "nova cidade". Atores nomeados e enredo definido, completa-se o cenário, situado no entorno da Marginal Pinheiros, novíssima fronteira do grande capital em São Paulo.

A obra elucida a trama de interesses, estratégias e trajetórias presentes na construção daquele pedaço da capital paulista, a partir de uma perspectiva que aborda todos os atores envolvidos. Mariana inclusive é muito feliz na escolha do título do livro, que pode dar ao leitor, no primeiro momento, a impressão de que a autora credita, às duas populações que são afetadas pela intervenção urbana, a condição comum de vítimas em um processo político pautado pela priorização de alguns interesses determinados em detrimento de outros conseqüentemente, excluídos. Não se trata disso, porém. Os parceiros nesse processo são capital e Estado. Em muitas passagens não é possível distinguir um e outro, tal a confusão de interesses na construção da "nova cidade". O que é evidente é a exclusão que promovem.

Acompanhando as Operações Urbanas "Faria Lima" e "Água Espraiada”, exemplos de parcerias entre 
gestão pública municipal e iniciativa privada, Mariana distingue com clareza não apenas a capacidade de mobilização e resistência dos dois grupos de moradores, como o próprio tratamento dispensado a cada um deles pelo poder público e pela mídia. Embora tratores não peçam licença, como afirma o título de um dos capítulos do livro, os moradores do entorno da Nova Faria Lima organizaram-se em associações, questionaram juridicamente a obra, alteraram seu traçado, puderam retardar o projeto de prolongamento da avenida e chamaram a atenção da mídia e dos círculos acadêmicos. Mas não puderam resistir à política de "fato consumado" de Maluf, acabaram indenizados pelo valor venal de seus imóveis e mudaram-se para outros bairros. Aos moradores do Jardim Edith o poder público dispensou o tratamento que historicamente se dispensa aos pobres no Brasil: ameaças, cooptação, violência. Além de arrancados de seu local de moradia e de terem suas casas reduzidas a entulho, contaram com indenizações irrisórias e foram deslocados, pela Prefeitura paulistana, para regiões distantes, nos extremos da cidade. Pela ação do poder público tiveram destruídos seus meios de ganhar a vida e os laços de sociabilidade que construíram ao longo de anos. A autora acerta ao manter os dois estudos de caso em paralelo, não apenas por apontar as diferenças entre ambos, mas sobretudo as semelhanças, que residem na dificuldade que tiveram em resistir, tanto os moradores de classe média do entorno da Nova Faria Lima quanto a população de baixa renda do Jardim Edith, ao rolo compressor das parcerias entre público e privado voltadas à reconfiguração daquela região da cidade, num cenário de disputa territorial de fato.

A criação da nova centralidade paulistana é um impressionante caso de combinação entre o velho e o novo. Junto com a chegada de grandes corporações transnacionais à cidade, da aplicação de novíssimas tecnologias de engenharia civil empregadas nos edifícios "pós-modernos" ali construídos e da retórica da necessidade do aumento da competitividade internacional da metrópole, supostamente inserida numa seara global em que as cidades lutam entre si por investimentos, reapresentam-se os conhecidíssimos esquemas que confundem negócios privados e a coisa pública, tão típicos do capitalismo que se formou neste país. A construção da "nova cidade" que surge em São Paulo reúne a antiga prática da expulsão, pelo Estado, das populações de baixa renda estabelecidas em áreas valorizadas pelo mercado imobiliário, a forma casuística de interpretação da legislação, de acordo com os grandes interesses, o aliciamento de lideranças populares, a aquiescência da mídia e a desinformação e/ou a indiferença da opinião pública. Acrescente-se à relação incestuosa estabelecida entre mercado e poder público no caso das operações Nova Faria Lima e Água Espraiada as denúncias, que vieram à tona nos últimos anos por iniciativa do Ministério Público, de superfaturamento das obras, mecanismo pelo qual se teriam beneficiado diretamente os principais responsáveis pela gestão municipal de São Paulo à época. Coroando a busca pelo lucro e a suposta má-fé no uso do dinheiro público, o processo de expulsão das populações do entorno da Nova Faria Lima, e, principalmente, do Jardim Edith, foi caracterizado por uma mentalidade calcada numa espécie de modernismo requentado, que busca justificar a concentração de investimentos públicos numa única região da cidade e que submete a discussão pública e os direitos da cidadania ao tal "progresso".

Dentre os muitos méritos do livro de Mariana, o que mais se destaca é a forma como ela retrata, com beleza e ternura, um processo extremamente brutal de exclusão social levado a cabo durante meses, ou anos, no coração da cidade, aos olhos de todos. Se por um lado Mariana mostra o ruído dos tratores e a força do dinheiro e da persuasão midiática postos a serviço desse novo ciclo "modernizador" que São Paulo atravessou há tão pouco tempo, por outro ela conforta-nos por meio do microfone aberto e da sensibilidade arguta com que capta as falas daqueles que, pelo menos em seu livro, foram os protagonistas dessa história. No epílogo do livro Mariana encontra alguns deles vivendo sob condições absolutamente inóspitas e insalubres, a dezenas de quilômetros de distância do Jardim Edith, em área de proteção de mananciais nas margens da Represa Billings. Foram lá instalados pela Prefeitura, numa ação que confronta a legislação ambiental. Fundaram no local o Jardim Edith II. O panorama do lugar é absolutamente desolador. Tanto quanto o que pode ser encontrado nas cercanias da "nova cidade", um enclave global que permanece rodeado por dezenas de favelas. Se as periferias parecem poder estender-se incessantemente, os limites geográficos para a expansão dessa nova centralidade parecem ter chegado ao fim, já que logo ali em frente, um pouco mais ao sul, ou na outra margem do rio Pinheiros, situa-se a porção mais pauperizada, excluída e violentada da Paulicéia (SPOSATI, 2000). E mesmo aqueles que trafegam apenas na Água Espraiada já devem ter percebido que os barracos estão de volta. Para desgosto dos que vêem no espaço público a potencialidade do lucro ou dos que apregoam que cidade boa é cidade limpa (nas mais variadas acepções que se possa atribuir a essa palavra), a realidade insiste em nos mostrar que as demandas sociais de fato parecem ter muito pouco a ver com os anseios assépticos do mercado. 
Wagner T. Iglecias (wiglecias@uol.com.br) é doutorando no Departamento de Sociologia da Universidade de São Paulo (USP).

\section{REFERÊNCIAS BIBLIOGRÁFICAS}

FRÚGOLI JR., H. 2000. Centralidade em São Paulo. Trajetórias, conflitos e negociações na metrópole. São Paulo : Cortez/Edusp/FAPESP.

MARICATO, E. 1996. Metrópole na periferia do capitalismo. Ilegalidade, desigualdade e violência. São Paulo: Hucitec.

ROLNIK, R. 1988. São Paulo, início da industrialização : o espaço e a política. In : KOWARICK, L. (org.). As lutas sociais e a cidade. São Paulo passado e presente. Rio de Janeiro : Paz e Terra.

. 1997. A cidade e a lei. Legislação, política urbana e territórios na cidade de São Paulo. São Paulo : Studio Nobel/FAPESP.

SPOSATI, A. (coord.). 2000. Mapa da exclusão-inclusão social da cidade de São Paulo. Dinâmica social dos anos 90. São Paulo : Pontifícia Universidade Católica de São Paulo/Polis/Instituto Nacional de Pesquisas Espaciais. 